九州大学学術情報リポジトリ

Kyushu University Institutional Repository

\title{
Effect of Wall Resistance on the Total Thermal Resistance of a Stacked Microchannel Heat Sink
}

\section{H. S. Shamsuddin}

School of Mechanical Engineering, Faculty of Engineering, Universiti Teknologi Malaysia

U. Abidin

School of Mechanical Engineering, Faculty of Engineering, Universiti Teknologi Malaysia

H. Abd-Zaidan

Middle Technical University, Institute of Technology Baghdad

N. Mohd-Ghazali

School of Mechanical Engineering, Faculty of Engineering, Universiti Teknologi Malaysia

https://doi.org/10.5109/4372270

出版情報 : Evergreen. 8 (1)，pp.138-145，2021-03. Transdisciplinary Research and Education Center for Green Technologies, Kyushu University

バージョン :

権利関係 : 


\title{
Effect of Wall Resistance on the Total Thermal Resistance of a Stacked Microchannel Heat Sink
}

\author{
H. S. Shamsuddin ${ }^{1}$, U. Abidin 1 , H. Abd-Zaidan ${ }^{2}$, N. Mohd-Ghazali ${ }^{1} *$ \\ ${ }^{1}$ School of Mechanical Engineering, Fac. of Engineering, Universiti Teknologi Malaysia, Malaysia \\ ${ }^{2}$ Middle Technical University, Institute of Technology Baghdad, Iraq \\ *Author to whom correspondence should be addressed: \\ E-mail:normah@mail.fkm.utm.my
}

(Received November 27, 2020; Revised January 30, 2021; accepted March 23, 2021).

\begin{abstract}
This paper reports on the different modeling approach of the total thermal resistance in a microchannel heat sink (MCHS); with wall resistance and the frequently used fin model, in comparison with experimental results. For a single stack MCHS, the wall model caused more than $10 \%$ difference but it can be extended to a stacked MCHS while the fin model could not, due to the adiabatic top condition. The wall resistance model is idealized, assuming a $100 \%$ efficient convective heat transfer while in the fin model $70 \%$ was the maximum. Meanwhile, stacking showed that at a constant flow rate, the thermal resistance could be reduced by $3 \%$ for a double stack, while increasing beyond that will decrease the thermal performance of the MCHS. The study showed the limits of models used and possible stacking of a MCHS for improved heat removal capability.
\end{abstract}

Keywords: microchannel heat sink; thermal resistance; wall conductive resistance; stacked

\section{Introduction and background}

Effective heat removal from integrated circuits (ICs) is considered a major factor in the development of Microprocessors aiming at high-performance computer systems and high heat flux applications ${ }^{1}$. Today's modern electronics with larger scale device integration systems lead to even greater power densities and operating temperatures ${ }^{2}$. Increasing power densities for better microprocessors will affect power consumption which means it is not economical for practical applications besides increasing the dependency on fossil fuels as explained by Fujisaki ${ }^{3}$. Barai and Saha ${ }^{4}$ said in Japan for an example, it is a must to create an economically sustainable infrastructure which means applications which increased power densities are not recommended.

Since the discovery of the microchannel heat sink (MCHS) for electronics cooling by Tuckerman and Pease in $1981^{5)}$, it has become a practical system till today and continuously being improved in meeting future demands. In a simple MCHS design model, a solid plate with parallel channels is attached on top of the microchip surface, generally made of silicon with an adiabatic cover sealed on top of the system to contain the heat. Initially, heat from the source is transferred by conduction to the solid wall surface attached to the microchip and via convection into the fluid pass using conventional coolants such as water ${ }^{5)}$ or air ${ }^{6,7)}$. Coolants have now advanced into nanofluids with spherical ${ }^{8,9)}$ and tube shape ${ }^{10,11)}$ particles suspended in base fluids to increase the heat transfer capability. The fluid removes the heat as it flows through the channels.

The heat sink technology also has been adopted by a larger heat exchanging system with minichannels with hydraulic diameter range between $200 \mu \mathrm{m}$ to $3 \mathrm{~mm}$ while microchannel range between $10 \mu \mathrm{m}$ to $200 \mu \mathrm{m}$ according to the classification by Kandlikar and Grande ${ }^{12}$. The technology advances into radial movement expanding system $^{13,14)}$, complex wall geometry such as triangular cavities ${ }^{15)}$ and zig-zag to increase surface area for convection ${ }^{16)}$, and topology design to decrease pressure drop ${ }^{17}$. However, some of these innovations are limited to minichannels only.

Since a microchannel is too small for channel geometry complexity compared to a minichannel, for very high heat dissipation in compact systems two-phase flow has been considered $^{18,19,20)}$. The establishment of reliable and accurate heat transfer coefficient has yet to be established for newer and more environmentally friendly refrigerants even for minichannels such as R-22, R134A, R744 ${ }^{21)}$, $\mathrm{R} 410 \mathrm{~A}, \mathrm{R} 407 \mathrm{C}^{22)}, \mathrm{R} 717^{23)}$ and $\mathrm{R} 290^{24,25)}$. A schematic of the water-cooled MCHS considered here is shown in Fig. 1 with the dimensions and thermal resistance, $R_{t h}$, of two experiments, A and B, from Tuckerman and Pease ${ }^{5)}$ listed in Table 1. 


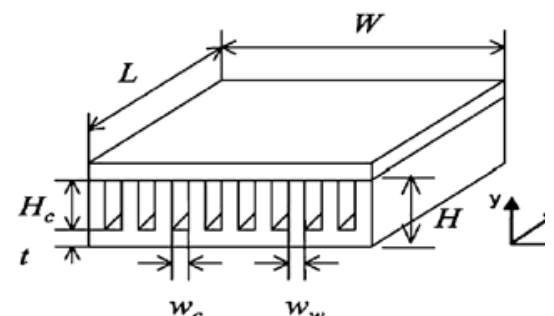

Fig. 1: Schematic structure of a rectangular cross section $\mathrm{MCHS}^{26)}$

Table 1: Dimensions of a MCHS ${ }^{5}$

\begin{tabular}{|l|c|c|}
\hline \multicolumn{3}{|c|}{ Tuckerman and Pease $^{5)}$} \\
\hline Type & A & B \\
\hline $\mathrm{t}(\mu \mathrm{m})$ & 256 & 213 \\
\hline $\mathrm{H}_{\mathrm{c}}(\mu \mathrm{m})$ & 302 & 320 \\
\hline $\mathrm{W}_{\mathrm{c}}(\mu \mathrm{m})$ & 50 & 56 \\
\hline $\mathrm{w}_{\mathrm{w}}(\mu \mathrm{m})$ & 50 & 44 \\
\hline $\mathrm{G}\left(\mathrm{cm}^{3} / \mathrm{s}\right)$ & $8.6 \times 10^{-6}$ & $4.7 \times 10^{-6}$ \\
\hline $\mathrm{R}_{\mathrm{th}}(\mathrm{K} / \mathrm{W})$ & 0.09 & 0.11 \\
\hline
\end{tabular}

The experimental data achieved by Tuckerman and Pease $^{5)}$ for such a system is as shown in Table 1 where the thermal performance was measured in terms of the thermal resistance, $R_{t h}$, according to the dimensions of the microchannel, material, and volumetric flow rate of deionized water at $23^{\circ} \mathrm{C}$.

Ever since the introduction of the MCHS, numerical models have been developed to represent the system in the investigations of the performance of the MCHS under various geometry, dimensions, flow conditions, and coolant types. Most often used model is the thermal resistance model due to its simple form and reliable outcomes as can be seen in the review by Adham et $\mathrm{al}^{27}$. And up to 2020, many studies involving MCHS research utilized the thermal resistance model ${ }^{28,29,30}$. The next commonly used model is the porous medium model ${ }^{31)}$. The outcomes of the models were often based on and compared with the landmark work of Tuckerman and Pease ${ }^{5)}$, shown in Table 2.

Table 2: Parameters in the MCHS ${ }^{5)}$

\begin{tabular}{|l|c|}
\hline Parameter & Value \\
\hline$L(\mathrm{~m})$ & $1 \times 10^{-2}$ \\
\hline$W(\mathrm{~m})$ & $1 \times 10^{-2}$ \\
\hline$k_{b}\left(\mathrm{~W} / \mathrm{m}^{\circ} \mathrm{C}\right)$ & 148 \\
\hline$\rho_{f}\left(\mathrm{~kg} / \mathrm{m}^{3}\right)$ & 997 \\
\hline$\mu_{f}\left(\mathrm{~kg} / \mathrm{m} \mathrm{s}^{\circ}\right.$ & $8.55 \times 10^{-4}$ \\
\hline$C_{p f}\left(\mathrm{~J} / \mathrm{kg}{ }^{\circ} \mathrm{C}\right)$ & 4179 \\
\hline$H_{b}(\mathrm{~m})$ & $1 \times 10^{-4}$ \\
\hline
\end{tabular}

As the number of fins was found to affect the thermal resistance both in modelling and experimental studies ${ }^{32}$, Lei et al. ${ }^{33)}$ also proposed a wall model for the single stack followed by Shao et al. ${ }^{34)}$ for a double-stack MCHS. It was found that the wall model is a better representation of the multi-stack MCHS. A multi-stack MCHS mitigates the rise of high stream wise temperature and thus reduces the thermal resistance and needed pumping power in Lu and Vafai $^{35}$ findings. Although most experimental studies only involved one stack, stacking would be possible as Back et al. fabricated a stacking layers of silicon to construct coolant passages to flow into microchannels using Deep Reactive-Ion Etching (DRIE) process ${ }^{36)}$ and stacking manufacturing is also being researched using silicon oxide $(\mathrm{SiO})$ on silicon surface ${ }^{37}$. With a wall model, it would definitely be able to extend to a multistack model of MCHS research in the nearest future. An adiabatic top above the single stack MCHS in the fin model made it currently impossible to extend to stacking of the MCHS. This study was completed to assess the significance of the wall resistance towards the total thermal resistance in modeling the thermal performance of a MCHS.

\section{Methodology}

Modeling with the thermal resistance has been used widely and the most common model adapts fin modeling where the walls between microchannels are treated as fins as they are very thin. However, for very small devices, the conductive wall thickness should be considered due to the length scale involved. This paper introduced the model of Zaidan $^{38)}$ where the wall is considered for conductive resistance and compared with the fin model by Adham et al. ${ }^{26)}$ referring to the experimentation results of Tuckerman and Pease ${ }^{5)}$.

\subsection{Model 1 (Fin)}

The fin model consists of a series arrangement of the thermal resistance focusing on a single channel as shown in Fig. 2. The heat flux flow from the bottom of the MCHS base (where it is directly in contact with the heat source) towards the microchannels via conduction. This is represented by $R_{\text {conductive }}$ (Eq.1). The model assumed the wall thickness between the microchannels as fins, which utilized the fin equation in the average heat transfer coefficient, $h_{\text {avg }}$, for the convective resistance, $R_{\text {convective }}$ (Eq.2). The third heat resistance, $R_{\text {fluid }}$ (Eq.3) in the series represents the heat energy absorbed in the fluid as it flows between the entrance and the exit of a microchannel according to the heat capacity of the fluid. As the model consisted of series configuration, the total thermal resistance is represented in Eq. 4 which is the total sum of all three resistances. 


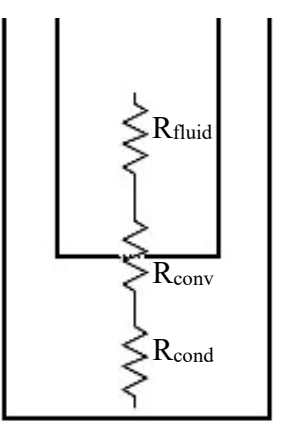

Fig. 2: Schematic diagram of Model 1 (fin)

$$
\begin{aligned}
& R_{\text {conductive }}=\frac{t}{k_{b}} \\
& R_{\text {convective }}=\frac{1}{h_{a v}} \cdot \frac{\left(1+\left[\frac{w_{w}}{w_{c}}\right]\right)}{\left(1+2\left[\frac{H_{c}}{w_{c}}\right] \eta\right)} \\
& R_{\text {capacitive }}=\frac{L}{C p_{f} \mu_{f}} \cdot \frac{2}{\operatorname{Re}} \cdot \frac{\left(1+\left[\frac{w_{w}}{w_{c}}\right]\right)}{\left(1+\left[\frac{H_{c}}{w_{c}}\right]\right)} \\
& R_{\text {total }}=R_{\text {conductive }}+R_{\text {convective }}+R_{\text {capacitive }}
\end{aligned}
$$

\subsection{Model 2 (Wall)}

The second model resistance is configured in series and parallel as the thickness between two microchannels is a wall with its own conductive resistance. Described by Shao et al. ${ }^{34)}$, a half channel and half wall are preferred in the wall model to ease simplification of schematics and calculations as shown in Fig. 3. Referring to the schematic, a parallel arrangement is formed due to the conductive resistance via wall, $R_{w}$, and convective resistance resulted by the flow of heat flux from the base to the fluid, $R_{b-f}$.

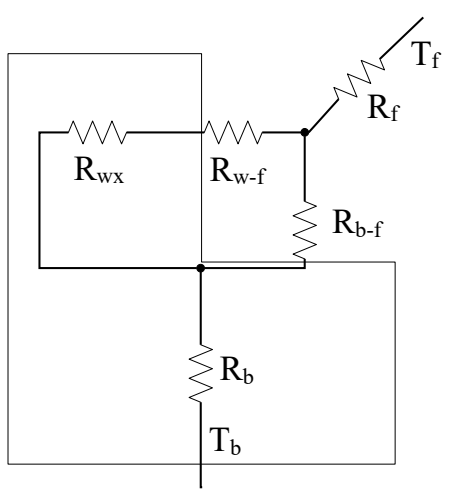

Fig. 3: Schematic diagram of Model 2 (wall)

Due to the half microchannel and wall being considered, the width of both wall and channel were divided by two for the conductive base resistance, $R_{b}$, as the heat flows from the lowest point of the base or substrate to the top reaching the wall and microchannel.

$$
R_{b}=R_{\text {base,cond }}=\frac{2 H_{b}}{k_{s}\left(w_{w}+w_{c}\right)}
$$

This is also applied to the conductive resistance of the wall, $R_{w x}$, as the width is halved in this model. In the wall region which consists of a two-dimensional flow, heat in the fin is not considered, only the $x$-direction was taken into the equation for a single stack. Heat flux was assumed to flow from the wall towards the channel or coolant.

$$
R_{w x}=R_{w a l l, c o n d}=\frac{w_{w}}{2 k_{b} H_{c} L}
$$

The channel height is unaffected for the convective thermal resistance at the surface of the wall towards the fluid, $R_{w-f}$, as compared to the convective thermal resistance from the base to fluid, $\underline{R}_{b-f}$. Both are independent and form a parallel thermal resistance schematic as referred to in Fig. 3.

$$
\begin{aligned}
& R_{w-f}=R_{\text {wall }, \text { conv }}=\frac{1}{h_{a v g} H_{c} L} \\
& R_{b-f}=R_{\text {base,conv }}=\frac{2}{h_{\text {avg }} w_{c} L}
\end{aligned}
$$

In Eq.9, the capacitance of the fluid is considered in the fluid thermal capacitance, $R_{f}$. Capacitance thermal resistance is directly affected by the condition of the coolant flow in each microchannel, which in this equation referred to as the Reynolds number.

$$
R_{f}=\frac{1}{\mu_{f} W c_{p f}} \cdot \frac{2}{\operatorname{Re}} \cdot \frac{w_{c}+w_{w}}{w_{c}+H_{c}}
$$

The total resistance, $R_{\text {total }}$, is summed according to the series and parallel configuration. For a multistack, additional stacks of a MCHS with the same dimensions are added on top of another as shown in Fig. 4. 


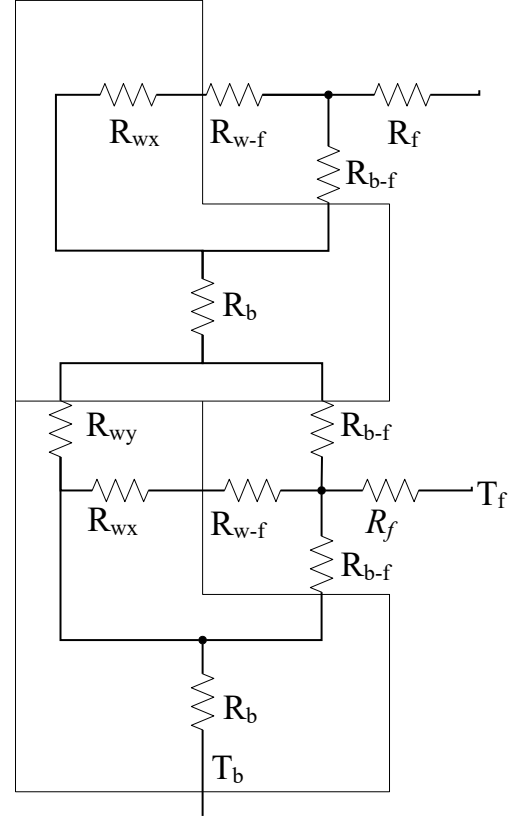

Fig. 4: Multistack of a MCHS

Therefore, there are additional resistances from the base of a MCHS towards the second $\operatorname{stack}^{8)}$ through the wall which in this case described as wall resistance in ydirection, $R_{w y}$, and between the coolant and the second stack with the same base to fluid resistance, $R_{b-f}$.

$$
R_{w y}=R_{\text {wall,cond }}=\frac{2 H_{c}}{k_{b} w_{w} L}
$$

\section{Results and Discussion}

The objective of this study is to compare the effects of the inclusion of the wall resistance in considering the thermal performance of a MCHS. The parameters for these models followed exactly as that shown in Table 1 and Table 2. The model with the nearest result to that of the experimental data indicates a better representation of the thermal performance. The result of the total thermal resistance is compared in Table 3 and Fig. 5.

Table 3. Thermal resistance of Tuckerman and Pease ${ }^{5)}$, Model 1 and Model 2.

\begin{tabular}{|c|c|c|c|}
\hline \multirow{2}{*}{ Model } & \multicolumn{3}{|c|}{$\mathbf{R}_{\text {th }}\left({ }^{\circ} \mathbf{C} / \mathbf{W}\right)$} \\
\cline { 2 - 4 } & T \& P Exp. & $\begin{array}{c}\text { Model 1 } \\
\text { (Fin) }\end{array}$ & $\begin{array}{c}\text { Model 2 } \\
\text { (Wall) }\end{array}$ \\
\hline A & 0.090 & 0.081 & 0.070 \\
\hline B & 0.110 & 0.102 & 0.090 \\
\hline
\end{tabular}

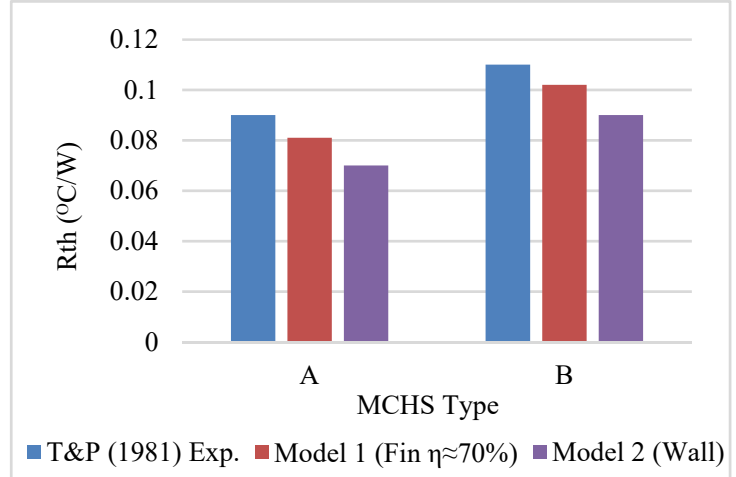

Fig. 5: Total thermal resistance against channel height for both models.

It can be seen clearly that for Model 2 the total thermal resistance is lower than the experimental data and Model 1. All the resistances in an experiment could of course cannot be represented mathematically. Although individually, the resistances contributing towards the overall heat transfer may be small but collectively they could have caused the difference in comparison with models representing the physical system. The fin model acquires a closer agreement with the experimental results with a difference of $0.009{ }^{\circ} \mathrm{C} / \mathrm{W}$ and $0.008{ }^{\circ} \mathrm{C} / \mathrm{W}$ for MCHS type A and B, respectively. The lowest difference is for type B with a channel height, $H_{c}$, of $320 \mu \mathrm{m}$, channel width, $w_{c}$, of $56 \mu \mathrm{m}$ and wall width of $44 \mu \mathrm{m}$, resulting in $7 \%$ difference with the experimental data. Type $\mathrm{B}$ has a $10 \%$ difference, which is still acceptable. However, for Model 2 which utilized the wall equations, the thermal resistance is low compared to the experimental results by Tuckerman and Pease ${ }^{5)}$. The reasons could be due to:

a) Conduction thermal resistance from the base of the MCHS to the top of the wall, $R_{w y}$, is not considered for a single stack in the wall resistance model.

b) The heat transfer rate from the base to the tip actually varies being most efficient at the bottom in the fin model.

c) Convective resistance from wall to fluid, $R_{w-f}$, was $100 \%$ efficient while in the fin model it was at $70 \%$ maximum.

To analyse the wall equation, Model 1 was assumed to be a $100 \%$ efficient and compared to Model 2 with the results listed in Table 4 and Table 5. The difference in the thermal resistance was determined in comparison with that of Tuckerman and Pease ${ }^{5}$ )

Table 4: Thermal resistance of Model 1 and Model 2 with $100 \%$ efficiency

\begin{tabular}{|c|c|c|c|}
\hline \multirow{2}{*}{ Model } & \multicolumn{3}{|c|}{$\mathbf{R}_{\text {th }}\left({ }^{\circ} \mathbf{C} / \mathbf{W}\right)$} \\
\cline { 2 - 4 } & $\begin{array}{c}\text { Model 1 } \\
(\text { Fin } \eta \approx \\
70 \%)\end{array}$ & $\begin{array}{c}\text { Model 1 } \\
(\text { Fin } \eta= \\
100 \%)\end{array}$ & $\begin{array}{c}\text { Model 2 } \\
(\text { Wall })\end{array}$ \\
\hline $\mathrm{A}$ & 0.081 & 0.070 & 0.070 \\
\hline $\mathrm{B}$ & 0.102 & 0.091 & 0.090 \\
\hline
\end{tabular}


Table 5. Percentage difference of Model 1 with $100 \%$ efficiency and Model 2 against Tuckerman and Pease ${ }^{5)}$

\begin{tabular}{|c|c|c|c|}
\hline \multirow{2}{*}{ Model } & \multicolumn{3}{|c|}{ Difference } \\
\cline { 2 - 4 } & $\begin{array}{c}\text { Model 1 (Fin } \\
\eta \approx 70 \%)\end{array}$ & $\begin{array}{c}\text { Model 1 } \\
(\text { Fin } \eta \approx \\
100 \%)\end{array}$ & $\begin{array}{c}\text { Model 2 } \\
(\text { Wall) }\end{array}$ \\
\hline $\mathrm{A}$ & $10 \%$ & $22 \%$ & $22 \%$ \\
\hline $\mathrm{B}$ & $7 \%$ & $18 \%$ & $18 \%$ \\
\hline
\end{tabular}

The wall model is identical with the fin model at $100 \%$ efficiency. The percentage difference reaches up to $22 \%$ for Type A and 18\% for Type B. The thermal resistance from the fin model with $100 \%$ fin efficiency is identical to the wall model. The Bi number for type A and B is below 0.1 , as shown in Table 6 , thus assuming that each channel wall behaves like a fin is reasonable.

$$
\mathrm{Bi}=\mathrm{h}_{\mathrm{avg}} \cdot \mathrm{t} / \mathrm{k}_{\mathrm{hs}}
$$

Table 6: Biot Number of the MCHS Types

\begin{tabular}{|l|c|c|}
\hline \multicolumn{3}{|c|}{ Variables } \\
\hline Type & A & B \\
\hline $\mathrm{Bi}$ & 0.095 & 0.07 \\
\hline
\end{tabular}

However, the fin model currently cannot be extended to represent a stacked MCHS due to the adiabatic cover. Although the difference between the wall resisatnce model and experimental data is quite significant, investigation of the outcomes with stacking is considered to look at the trend of the thermal resistance. Each added stack will now have to include the base resisatcne at each level. Improvement to the wall resistanc model can be made in future by considering the conduction resistance from base of the MCHS to the top of its wall before being removed by the wall to the coolant through convection. The results of the modeling of a single and multistack MCHS are shown in Table 7. The multistack MCHS was continued to up to four stacks in this study.

Table 7: Total thermal resistance against channel height for

\begin{tabular}{|l|c|c|}
\hline \multicolumn{2}{|c|}{ four stacks. } \\
\hline Type & \multicolumn{2}{|c|}{$\mathbf{R}_{\text {th }}\left({ }^{\circ} \mathbf{C} / \mathbf{W}\right)$} \\
\hline 1 Stack & A & B \\
\hline 2 Stacks & 0.070 & 0.090 \\
\hline 3 Stacks & 0.068 & 0.089 \\
\hline 4 Stacks & 0.075 & 0.099 \\
\hline
\end{tabular}

The lowest thermal resistance of $0.068^{\circ} \mathrm{C} / \mathrm{W}$ was obtained for the double stack model Type A with a reduction of $3 \%$. Exceeding 2 stacks, the thermal resistance increases due to the decrease in the Reynolds number in each microchannel. Stacking the MCHS will result in more microchannels with a constant input coolant flow rate, $G$, into the system and consequently results in a lower velocity and Reynolds number in every microchannel. As the Reynolds number decreases, this results directly to the rise of the capacitive resistance, $R_{f}$, as referred to in Eq 9. Therefore, with a constant input of coolant flow rate, the best result can be achieved with a double stack of the MCHS. The Reynolds number plays a significant role in deciding on a multistack performance as more stacks directly increases the fluid capacitance resistance, $R_{f}$.

\section{Conclusion}

The total thermal resistance for the fin model and wall resistance model has been successfully compared with the landmark experimental work of Tuckerman and Pease ${ }^{4}$. The fin assumption, Model 1, shows a better agreement compared to the wall model since the microchannel wall width is thin with a Biot number less than 0.1. The model currently, however, could not be extended to a stacked MCHS due to the adiabatic cover assumption. The wall resistance model is suitable when a stacked MCHS is considered. At a constant flow rate, doubling the stack lowers the thermal resistance and this provides possible application for better heat removal capacity of a MCHS. Beyond 2, the thermal resistance rises.

\section{Acknowledgements}

The authors acknowledge the funding from the Research University Grant Universiti Teknologi Malaysia, GUP Vot19H60, to complete this research. 


\section{Nomenclature}

\begin{tabular}{|c|c|}
\hline$C_{p}$ & heat capacity $(\mathrm{J} / \mathrm{kg} . \mathrm{K})$ \\
\hline$G$ & volumetric flow rate $\left(\mathrm{m}^{3} / \mathrm{s}\right)$ \\
\hline$h$ & height (m) \\
\hline$h_{\text {avg }}$ & average heat transfer coefficient $\left(\mathrm{W} / \mathrm{m}^{2} . \mathrm{K}\right)$ \\
\hline$h_{\text {avg,fin }}$ & $\begin{array}{l}\text { average fin heat transfer coefficient } \\
\left(\mathrm{W} / \mathrm{m}^{2} . \mathrm{K}\right)\end{array}$ \\
\hline$k$ & thermal conductivity $(\mathrm{W} / \mathrm{m} . \mathrm{K})$ \\
\hline$L$ & length (m) \\
\hline$R$ & thermal resistance $(\mathrm{K} / \mathrm{W})$ \\
\hline$t$ & substrate/base thickness (m) \\
\hline$W, w$ & width (m) \\
\hline$R_{b}$ & $\begin{array}{l}\text { conduction resistance from bottom surface of } \\
\text { the base }\end{array}$ \\
\hline$R_{w x}$ & $\begin{array}{l}\text { conduction resistance from the wall to the } \\
\text { channel or coolant }\end{array}$ \\
\hline$R_{w y}$ & $\begin{array}{l}\text { conduction resistance from the upper base to } \\
\text { the solid medium of the wall }\end{array}$ \\
\hline$R_{b-f}$ & $\begin{array}{l}\text { convection resistance from base to the } \\
\text { coolant via microchannel }\end{array}$ \\
\hline$R_{w-f}$ & $\begin{array}{l}\text { convection resistance from wall to the } \\
\text { coolant via microchannel }\end{array}$ \\
\hline$R_{f}$ & $\begin{array}{l}\text { capacitance resistance of the fluid receiving } \\
\text { energy from the heat fluxes }\end{array}$ \\
\hline
\end{tabular}

Greek symbols

$\eta \quad$ fin efficiency

$\begin{array}{cl}\text { Subscript } & \\ c & \text { channel } \\ f & \text { fluid } \\ w & \text { wall }\end{array}$

\section{References}

1) P. Smakulski, and S. Pietrowicz, "A review of the capabilities of high heat flux removal by porous materials, microchannels and spray cooling techniques," Applied Thermal Engineering, 104 636646

(2016). doi:10.1016/j.applthermaleng.2016.05.096.

2) S.M.S. Murshed, and C.A.N. de Castro, "A critical review of traditional and emerging techniques and fluids for electronics cooling", Renew Sust Energ Rev., $\quad 78 \quad 821-833 \quad$ (2017). doi:10.1016/j.rser.2017.04.112.

3) T. Fujisaki, "Evaluation of Green Paradox: Case Study of Japan," Evergreen, 5 (4) 26-31 (2018) doi:10.5109/2174855.

4) M. Barai, and B. Saha, "Energy Security and Sustainability in Japan." Evergreen Joint J Nov
Carbon Resour Sci Green Asia Strategy, 2 (1) 49-56 (2015). doi:10.5109/1500427

5) D.B. Tuckerman, and R.F. Pease, "High-performance heat sinking for VLSI," IEEE Electron Device Lett. 5 126-129 (1981). doi: 10.1109/EDL.1981.25367

6) N. Goldberg, "Narrow Channel Forced Air Heat Sink," IEEE Transactions on Components, Hybrids, and Manufacturing Technology, 7 (1) 154-159 (1984). doi: 10.1109/TCHMT.1984.1136326.

7) M.B. Kleiner, S.A. Kuhn, and K. Haberger, "High performance forced air cooling scheme employing microchannel heat exchangers," IEEE Transactions on Components, Packaging, and Manufacturing Technology: Part A, 18 (4) 795-804 (1995). doi:10.1109/95.477466.

8) Z.X. Li, U. Khaled, A.A.A.A. Al-Rashed, M. Goodarzi, M.M. Sarafraz, and R. Meer, "Heat transfer evaluation of a micro heat exchanger cooling with spherical carbon-acetone nanofluid," International Journal of Heat and Mass Transfer, 149 (2020). doi:10.1016/j.ijheatmasstransfer.2019.119124.

9) M. Ding, C. Liu, and Z. Rao, "Experimental investigation on heat transfer characteristic of TiO2$\mathrm{H} 2 \mathrm{O}$ nanofluid in microchannel for thermal energy storage," Applied Thermal Engineering, 160 (2019). doi:10.1016/j.applthermaleng.2019.114024.

10) S. Halelfadl, A.M. Adham, N. Mohd-Ghazali, T. Mare, P. Estelle, and R. Ahmad, "Optimization of thermal performances and pressure drop of rectangular microchannel heat sink using aqueous carbon nanotubes based nanofluid," Applied Thermal Engineering, $62 \quad$ (2) 492-499 (2014). doi: 10.1016/j.applthermaleng.2013.08.005.

11) N. Mohd-Ghazali, P. Estellé, S Halelfadl, T. Maré, C. S. Tng, and U. Abidin, "Thermal and hydrodynamic performance of a microchannel heat sink with carbon nanotube nanofluids," Journal of Thermal Analysis and Calorimetry, $138 \quad$ (2) 937-945 (2019). doi:10.1007/s10973-019-08260-2.

12) S. G. Kandlikar, and W. J. Grande, "Evolution of Microchannel Flow Passages-- Thermohydraulic Performance and Fabrication Technology," Heat Transfer Engineering, 24 (1) 3-17 (2003). doi: 10.1080/01457630304040.

13) S. Hong, C. Dang, E. Hihara, H. Sakamoto, and M. Wada, "Improved two-phase flow boiling in a minichannel heat sink for thermal management of information and communication technology (ICT) equipment," Applied Thermal Engineering, 181 (2020). doi:10.1016/j.applthermaleng.2020.115957.

14) S. Hong, C. Dang, and E. Hihara, "Experimental investigation on flow boiling characteristics of radial expanding minichannel heat sinks applied for twophase flow inlet," International Journal of Heat and 
Mass Transfer, $151 \quad$ (2020). doi: 10.1016/j.ijheatmasstransfer.2020.119316.

15) Y.F. Li, G.D. Xia, D.D. Ma, J.L. Yang, and W. Li, "Experimental investigation of flow boiling characteristics in microchannel with triangular cavities and rectangular fins," International Journal of Heat and Mass Transfer, 148 (2019). doi:10.1016/j.ijheatmasstransfer.2019.119036.

16) D.D. Ma, G.D. Xia, L.X. Zong, Y.T. Jia, Y.X. Tang, and R.P. Zhi, "Experimental investigation of flow boiling heat transfer performance in zigzag microchannel heat sink for electronic cooling devices," International Journal of Thermal Sciences, 145 (2019). doi:10.1016/j.ijthermalsci.2019.106003.

17) S. Zheng, and P.S. Lee, "Topology optimization of liquid-cooled microchannel heat sinks: An experimental and numerical study," International Journal of Heat and Mass Transfer, 142 (2019). doi:10.1016/j.ijheatmasstransfer.2019.07.051.

18) A.S. Syahrul, J. T. Oh, N. Mohd-Ghazali, A. Robiah, and Y. Mohd-Yunos, "Entropy Generation Minimization of Two-Phase Flow in a Mini Channel with Genetic Algorithm," Evergreen, 6 (1) 39-43 (2019). doi:10.5109/2321004.

19) G. Liang, and I. Mudawar, "Review of single-phase and two-phase nanofluid heat transfer in macrochannels and micro-channels," International Journal of Heat and Mass Transfer, 136 324-354 (2019). doi:10.1016/j.ijheatmasstransfer.2019.02.086.

20) J.T Oh, A.S Pamitran, K.I. Choi, and P. Hrnjak, "Experimental investigation on two-phase flow boiling heat transfer of five refrigerants in horizontal small tubes of $0.5,1.5$, and $3.0 \mathrm{~mm}$ inner diameters," Int $J$ Heat Mass Transfer, 54 9-10 (2011). doi:10.1016/j.ijheatmasstransfer.2010.12.021.

21) K.I. Choi, A.S. Pamitran, C.Y. Oh, and J.T. Oh, "Boiling heat transfer of R-22, R-134a, and CO2 in horizontal smooth minichannels," International Journal of Refrigeration, 30 (8) 1336-1346 (2007). doi:10.1016/j.ijrefrig.2007.04.007.

22) K.I. Choi, A.S. Pamitran, J.T. Oh, and H.K. Oh, "Effect on boiling heat transfer of horizontal smooth minichannel for R-410A and R-407C," J Mech Sci Technol, $19 \quad 156-163 \quad$ (2005). doi:10.1007/BF02916114.

23) G.M. Normah, J.T. Oh, N.B. Chien, K.I. Choi, and A. Robiah, "Comparison of the optimized thermal performance of square and circular ammonia-cooled microchannel heat sink with genetic algorithm," Energy conversion and management, 102 59-65 (2015). doi:10.1016/j.enconman.2015.02.008.

24) A.S. Pamitran, S. Novianto, N Mohd-Ghazali, N Nasruddin, and R Koestoer, "Investigation on void fraction for two-phase flow pressure drop of evaporative R-290 in horizontal tube," Jurnal Teknologi, $78 \quad$ (8) 97-104 (2016). doi:10.11113/jt.v78.9590.
25) A.S. Pamitran, S. Novianto, and S.A. Santoso, "Intermittent Flow Pattern on Two Phase Flow Boiling with Horizontal Microchannel," Evergreen, $7 \quad$ (1) 150-154 (2020). doi: $10.5109 / 2740972$.

26) A.M. Adham, N. Mohd-Ghazali, and R. Ahmad, "Optimization of Nanofluid-cooled microchannel heat sink," Thermal Science, 20 (1) 109-118 (2016). doi:10.2298/TSCI130517163A.

27) A.M. Adham., N. Mohd-Ghazali, and R. Ahmad, "Optimization of an ammonia-cooled rectangular microchannel heat sink using multi-objective nondominated sorting genetic algorithm (NSGA2)," Heat Mass Transfer, 48 1723-1733 (2012). doi:10.1007/s00231-012-1016-8.

28) N. Mohd-Ghazali, P. Estellé, S. Halelfadl, T. Maré, T.C. Siong, and U. Abidin, "Thermal and hydrodynamic performance of a microchannel heat sink with carbon nanotube nanofluids," Journal of Thermal Analysis and Calorimetry, 138 (2) 937-945 (2019). doi:10.1007/s10973-019-08260-2.

29) X. Xiang, Y. Fan, W. Liu, and A. Fan, “Comparison between thermal resistances of optimized waterbased and gallium-based heat sinks using the genetic algorithm," International Journal of Numerical Methods For Heat \& Fluid Flow, 30 (3) 1388-1406. doi:10.1108/hff-07-2019-0590.

30) Z. He, Y. Yan, S. Feng, X. Li, and Z. Yang, "Numerical study of thermal enhancement in a microheat sink with ribbed pin-fin arrays," Journal of Thermal Analysis And Calorimetry, (2020). doi:10.1007/s10973-020-09739-z.

31) F. Lim, S. Abdullah, and I. Ahmad, "31 Numerical Study of Fluid Flow and Heat Transfer in Microchannel Heat Sinks using Anisotropic Porous Media Approximation," Journal Of Applied Sciences, 10 (18) 2047-2057. doi:10.3923/jas.2010.2047.2057.

32) R.W. Knight, J.S. Goodling, and B.E. Gross, "Optimal thermal design of air cooled forced convection finned heat sinks - experimental verification," IEEE Transactions on components, Hybrids and Manufacturing Technology, 15 (5) 754760 (1992). doi:10.1109/33.180040.

33) N. Lei, P. Skandakumaran, and A. Ortega, "Experiments and Modeling of Multilayer Copper Minichannel Heat Sinks in Single-Phase Flow," Thermal and Thermomechanical Proceedings 10th Intersociety Conference on Phenomena in Electronics Systems, 2006. ITHERM 2006. 9-18 (2006). doi:10.1109/ITHERM.2006.1645318.

34) B. Shao, L. Wang, and J. Li, “Application of thermal resistance network model in optimization design of micro-channel cooling heat sink," Int J Numer Method H., $19 \quad(3-4) \quad 535-545 \quad$ (2009). doi:10.1108/09615530910938425.

35) S. Lu, and K. Vafai, "A comparative analysis of innovative microchannel heat sinks for electronic 
cooling," Int Commun Heat Mass, 76 271-284 (2016). doi:10.1016/j.icheatmasstransfer.2016.04.024.

36) D. Back, K.P. Drummond, M.D. Sinanis, J. A. Weibel, S. V. Garimella, D. Peroulis, and D. B. Janes, "Design, Fabrication, and Characterization of a Compact Hierarchical Manifold Microchannel Heat Sink Array for Two-Phase Cooling," IEEE Transactions on Components, Packaging and Manufacturing Technology, 9 (7) 1291-1300 (2019). doi:10.1109/TCPMT.2019.2899648.

37) A.S. Idris, S. Ghosh, and K. Hamamoto, "A MultiLayer Stacked All Sol-Gel Fabrication Technique for Vertical Coupled Waveguide," Evergreen, 4 (2/3) 1217 (2017). doi:10.5109/1929657.

38) H. Zaidan, R. Ahmad, and N. Mohd-Ghazali, "Optimization of a stacked microchannel heat sink using nanofluids $\left(\mathrm{AL}_{2} \mathrm{O}_{3}-\mathrm{H}_{2} \mathrm{O}\right)$ with multiobjective optimization of thermal resistance and pressure drop," 2018 IEEE 5th International Conference on Smart Instrumentation, Measurement and Application (ICSIMA), $\quad 1-7 \quad$ (2018). doi: 10.1109/ICSIMA.2018.8688797. 